Simple planning and a little discipline can turn an ordinary presentation into a lively and engaging

\title{
Conducting Effective Presentations
}

\author{
by Peter Malvicini and Albert Dean Atkinson
}

\section{Rationale}

From interviews and our own observations, the following scenario is common: the speaker at a seminar shares about 30 slides, skipping over many. Time goes on....and on. Some participants lose interest; others become distracted; some even slip out. Finally, the sponsor says, "Time has run out, but maybe we can have one or two questions." Yet it looked as though the speaker had just reached the heart of the matter and it was over. What happened?

In most organizations, staff are busy and they vote with their feet. If they are bored or not actively engaged, they will

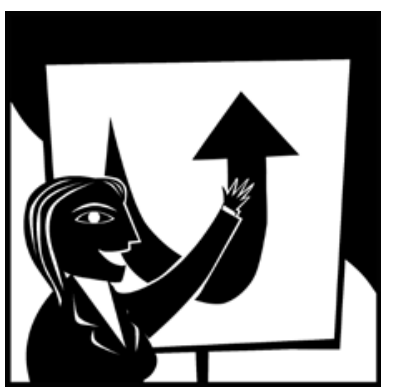
find excuses to leave. Some will never return to presentations conducted by the same speaker. The good news is that guidelines for conducting effective presentations are simple and do not depend on the speaking ability of the person sharing the message.

\section{Not, "How should I Talk?" but "How do they Learn?"}

Most speakers ask the wrong questions. Their efforts are dedicated to the substantive preparation of content ("What should I say?") and pay too little attention to the most important questions: "Who is my audience? and How will participants learn best?" Years of research on adult learning tell us adults learn best when

- The learning purpose and boundaries are clear. The invitation, welcome address, and introduction all orient participants to why they are there and what they can expect.

- Participants first establish common ground by sharing experiences or perspectives.

- Ideas can be shared freely in open environments.

- Ideas are heard before they are critiqued.

- Participants question assumptions driving their behavior and consider alternatives.

- The learning is based on the person's own experience.

- Participants engage actively rather than receive information passively.

- The speaker works with a variety of methods (and senses) - different from typical daily routines.

- The presentation is future-oriented and does not focus on problem solving. ${ }^{1}$ This

Nothing is wrong with problem solving, but it often traps energy. A strategic approach only addresses problems they are barriers to critical action. According to Carl Jung - problems tend to resolve or "fall off the radar" naturally: "All the greatest and most important problems of life are fundamentally insoluble...They can never be solved, but only outgrown. This 'outgrowth' proved on further investigation to require a new level of consciousness. Some higher or wider interest appeared on the patient's horizon, and through this broadening of his or her outlook the insoluble problem lost its urgency. It was not solved logically in its own terms but faded when confronted with a new and stronger life urge." 
creates anticipation as participants consider the implications for changes in practice.

- Topics apply directly to the professional work of participants and they mull it over next steps before they leave the room.

\section{Full Disclosure}

Let participants know what the seminar is about and give details of who will be sharing information. The opportunities include

- a visitor from a partner agency;

- the release of a study, report, or evaluation;

- a case study of a particular project;

- a new technology, tool, or concept; and

- a perspective or inspirational talk from a leader or respected expert.

If the seminar is given primarily by a consultant marketing a tool or expertise, the announcement will need to make that clear.

\section{Share Expectations}

Without being condescending, ask the speaker what his or her approach will be and whether you can see their slides in advance. A complex game plan or an unrealistic number of slides are good warning signs. Share these Knowledge Solutions with them as another way to facilitate preparation.

\section{Agree on a Length of Time in Advance}

If the event is a 1-hour presentation, time will pass quickly. One approach is to (i) take 20 minutes for a formal presentation; (ii) move to a question-and-answer session and, if time permits; (iii) hold a constructive group discussion. Better still, if possible, integrate brief questions after certain sections of the presentation instead of saving them for last.

\section{Twenty-Minute Attention Span}

Even if your speaker is spellbinding, research shows that most people lose interest after 20 minutes. If the presentation spans one hour, it should be broken up with questions and answers or open discussions. Better to leave the group wanting more, than wishing you had given less.

\section{Tell your Story}

Illustrations and anecdotes are key to making points effectively and relating to participants.

\section{Takeaways}

Supplement the presentation with a brief handout (not merely a copy of the slides) — takeaways add value and catalyze follow-through.

\section{Discussion Questions}

Ask the speaker to craft a few discussion questions in advance. Questions that draw experience work best. Analytical questions are second best. Questions about how ideas might be applied are more difficult. For example: (i) What is your experience in this area? (ii) Why do you think it worked that way? (iii) What can be done differently in the future?

\section{Organizing a Presentation}

In the introduction to the movie, The Prestige, the magician explains that there are three parts to every illusion. The first part is the pledge where the audience is told what they will see in order to capture attention. The second is the turn at which point the trick is performed. Third, the magician restores what he made disappear - it is a moment of awe and appreciation. "Ta-da!" Though not magic, research in communication and adult 


\section{Conducting Effective Presentations}

learning shows that even a brief presentation should follow a similar sequence. For this we can use hook-looktook:

- Hook. The very start of any presentation should answer the participants' unstated question, "What's in it for me?" This effectively draws people in, helping them quickly relate the topic to their experience (past, present, or future). Relevance is established. An effective hook can be a question or a brief story. The speaker should not wait until the end of the presentation to confirm the relevance of the message. Even before the presentation begins, the speaker should display the title of the presentation as participants seat themselves. This allows participants to prepare for the topic. Better yet, a pre-presentation might automatically loop introductory slides to give the audience background information.

- Look. This is the heart of the presentation, where the concepts and experiences are explained, illustrated, and examined. A seminar is different from a workshop - the presenter must be selective and synthetic. In many cases, introducing a topic and piquing participant interest are all one can reasonably expect in the time frame. A few well-placed illustrations or stories can pull a presentation nicely together.

- Took. Most speakers would like participants to apply or use what they learn in their professional work. Should participants do anything with the knowledge gained from the seminar? If the answer is yes, they are unlikely to do anything they do not discuss at the seminar. Application is not automatic - even the best seminars are quickly forgotten. If there is a specific opportunity to follow up or take a next step, try to "close the deal" at the seminar.

\section{Slide Maxims}

- Follow the Rule of 7 (or 777). It recommends a maximum of 7 lines of text on any slide, a maximum of 7 words on any one line, and a maximum of 7 slides in a 20-minute talk.

- Do not read your slides. Most participants read just as well. Paraphrasing the content works, as does illustrating it.

- Choose your fonts carefully. Font selection can help or hurt a presentation. Sans serif fonts (such as Arial) are best used for titles, while serif fonts (such as Times New Roman) make the text of the main body easier to read. ${ }^{22}$

- Use subtle transition effects. When changing slides, avoid dizzying effects such as elaborate fade-ins.

- Do not skip slides. Edit the presentation in advance based on the time given. "Recycled" talks need to be adapted to the particular group.

- Use graphics prudently. A picture is worth a thousand words. Full slide photographs or clearly illustrated diagrams can be inserted every three to five slides to provide visual learners with a medium appealing to their senses. Similarly, short audio clips reinforce concepts for audio learners, while short video clips meet the needs of both audio and visual learners.

- Evaluate the use of slides. It sounds like heresy but not every presentation benefits from slides. In some cases, a handout with informal sharing of experience or "stories" is more effective. Try it for a change.

\section{On the Day of the Presentation}

The speaker should arrive at the venue at least 15 minutes in advance to check the sound system, projector, computer connection, and Internet connection. If using a remote control for slide advancement or laser pointer, he or she should become comfortable with how they work. Nothing is more frustrating to participants than watching a presenter attempt to get the slides to show up on a projector, and then have them fumble with a remote control or laser pointer while they speak.

And you can read them up to $20 \%$ faster, as serifs help the eye tie letters together. 


\section{Knowledge}

\section{Preparation}

A little preparation, when it comes to the conducting presentations, is much better than none. But, not all the ideas in these Knowledge Solutions shoulde be applied at once. Presenters should try a few and see what happens.

\section{For further information}

Contact Peter Malvicini, strategic consultant (pgm1@cornell.edu), or Albert Dean Atkinson, Head of Information Resources and Services, Asian Development Bank (adatkinson@adb.org).

\section{Asian Development Bank}

$A D B$, based in Manila, is dedicated to reducing poverty in the Asia and Pacific region through inclusive economic growth, environmentally sustainable growth, and regional integration. Established in 1966, it is owned by 67 members - 48 from the region. In 2007, it approved $\$ 10.1$ billion of loans, $\$ 673$ million of grant projects, and technical assistance amounting to $\$ 243$ million.

...........................................................

Knowledge Solutions are handy, quick reference guides to tools, methods, and approaches that propel development forward and enhance its effects. They are offered as resources to ADB staff. They may also appeal to the development community and people having interest in knowledge and learning.

The views expressed in this publication are those of the authors and do not necessarily reflect the views and policies of the Asian Development Bank (ADB) or its Board of Governors or the governments they represent. ADB encourages printing or copying information exclusively for personal and noncommercial use with proper acknowledgment of ADB. Users are restricted from reselling, redistributing, or creating derivative works for commercial purposes without the express, written consent of ADB.

Asian Development Bank

6 ADB Avenue, Mandaluyong City

1550 Metro Manila, Philippines

Tel +6326324444

Fax +6326362444

knowledge@adb.org

www.adb.org/knowledgesolutions 